\title{
Os impactos da Covid-19 nas áreas da Ciência da Informação
}

\author{
Murilo Bastos da Cunha \\ Universidade de Brasília, Faculdade de Ciência da Informação, Brasília, DF, Brasil \\ murilobc@unb.br
}

DOI: https://doi.org/10.26512/rici.v13.n3.2020.33373

Recebido/Recibido/Received: 2020-08-08

Aceitado/Aceptado/Accepted: 2020-08-20

Resumo: O editorial analisa os impactos que a pandemia está provocando em algumas áreas da Ciência da Informação, notadamente nos arquivos, bibliotecas, museus e na comunicação científica. Além disso, são comentados os artigos incluídos no terceiro número de 2020 da Revista Ibero-Americana de Ciência da Informação.

Palavras-chave: Acesso aberto. Covid-19. Comunicação científica.

Los impactos de Covid-19 en las áreas de Ciencias de la Información

Resumen: El editorial analiza los impactos que está provocando la pandemia en algunas áreas de las Ciencias de la Información, especialmente en archivos, bibliotecas, museos y en la comunicación científica. Además, se comentan los artículos incluidos en el segundo número de 2020 de la Revista lberoamericana de la Ciencia de la Información.

Palabras clave: Acceso abierto. Covid-19. Comunicación científica.

\section{The impacts of Covid-19 in the areas of Information Science}

Abstract: The editorial analyzes the impacts that the pandemic is causing in some areas of Information Science, notably in archives, libraries, museums and in scientific communication. In addition, the articles included in the third issue of 2020 of the Iberic-American Journal of Information Science are commented. Keywords: Open access. Covid-19. Scientific communication.

Caro leitor,

Em setembro de 2020, após mais de seis meses, a pandemia da Covid-19 já tinha se espalhado pelos continentes, provocando os mais variados transtornos no dia a dia das pessoas físicas e jurídicas. E essa crise global parece que continuará por algum tempo. Somente a partir do início da vacinação em massa - no momento existem dezenas de vacinas sendo pesquisadas em laboratórios de diversos países - é que se vislumbrará um possível alívio contra essa epidemia.

Assim, este editorial irá focar os impactos que a pandemia está provocando em algumas áreas da Ciência da Informação, notadamente nos arquivos, bibliotecas, museus e na comunicação científica. Os profissionais dessas áreas estão passando por momentos de incertezas, considerando que bibliotecas, arquivos, e museus estão fechados e/ou funcionando de forma precária. 
No contexto da educação, algumas instituições de ensino estão estimulando o ensino a distância e, com isto, uma ferida social ficou mais visível: a falta de acesso à internet por uma grande parcela da população - a chamada "brecha digital". Como decorrência dessa mazela digital, nem todos os alunos podem usufruir das aulas em linha, ficando, portanto, à margem do processo educacional.

As políticas públicas também sentiram o impacto. Num momento em que as instituições da nossa área mais precisam de aportes orçamentários parece que as verbas públicas serão reduzidas! Com o desemprego crescente os governos federais e muitos estaduais, foram cobrados a lançarem mão do "auxílio emergencial". Esse auxílio tem chegado a milhões de brasileiros, importando num custo mensal de mais de 50 bilhões de reais. 0 auxílio emergencial é um benefício instituído pela Lei n. 13.982/2020 e aprovado pelo Decreto n. 10.316 (BRASIL. Decreto n. 10.316), que prevê o repasse de 600 reais mensais (inicialmente por três meses) a trabalhadores informais e de baixa renda, microempreendedores individuais e também contribuintes individuais do Instituto Nacional do Seguro Social (INSS). O objetivo do auxílio é mitigar os impactos econômicos e a vulnerabilidade social que serão causados pela pandemia de Covid-19.

No início da pandemia, os bibliotecários foram surpreendidos com o fechamento forçado de inúmeras instituições educacionais e/ou culturais, e entre elas, a biblioteca. Aos poucos, diversas iniciativas foram iniciadas por esses profissionais visando garantir o mínimo de acesso em linha aos recursos digitais armazenados nos acervos. No Brasil, essas ações cresceram tanto que a FEBAB (2020) organizou um diretório, denominado Informação em quarentena, classificado por categorias e com links para as iniciativas bibliotecárias.

Esforços foram feitos para garantir que os usuários da biblioteca tivessem acesso a recursos gratuitos, e várias editoras decidiram dar acesso gratuito a algumas de suas coleções que até então precisavam de assinaturas para se obter acesso.

No que tange à comunicação pode-se afirmar que depois do Covid-19 nada será igual como antes. Paradigmas serão mudados. É possível que a comunicação científica também passará por reformas. $\mathrm{O}$ valor da ciência aberta (maior transparência, dados abertos e acesso aberto aos resultados da pesquisa) tornou-se cada vez mais óbvio durante a atual crise provocada pela Covid-19. Tanto os aspectos positivos (relato rápido e compartilhamento de informações), quanto os negativos (o excesso de ciência ruim sendo publicada como préimpressão e promovida pela mídia convencional sem a adequada curadoria por parte dos pares) agora são evidentes, com o bom geralmente superando o ruim.

Belli et al. (2020) apontam que 
a porcentagem de artigos de acesso abeerto sobre o coronavirus para o periodo 2001-2020 é de 59,2\%, porém, se nos centramos em 2020, as cifras aumentaram até $91,4 \%$, devido o compromisso dos editores comerciais com a emergência (tendo proporcionado acesso gratuito a seus conteúdos). Por outro lado, é preciso destacar que o fenômeno pandêmico cedeu lugar ao tipo de acesso baseado na via Bronze, ou seja, sem garantia de acesso aberto perene, e dependente da boa vontade das editoras comerciais. São números muito relevantes, nunca antes alcançados. Os editores comerciais assumem implicitamente que o acesso aberto garante melhores resultados e eficácia. É importante que essa prática continue após a pandemia de Covid-19 e que possa ser estendida a todos os tópicos.

O acesso aberto se baseia no conceito de que o conhecimento é um bem público, mas reconhece que há custos e esforços necessários para produzir e manter esse bem público. Apesar da evidência da importância de mudar para um ambiente de ciência aberta para pesquisa, o deblacle econômico criados pela pandemia vão tornar o progresso necessário difícil e lento.

De qualquer forma, o processo editorial dos periódicos científicos pós-pandemia precisa ser mais célere na avaliação e publicação das novas descobertas - a rapidez na recente divulgação das pesquisas sobre a Covid-19 mostrou que isto é possível, mesmo com as dificuldades de se manter altos padrões de qualidade dos conteúdos. Ao mesmo tempo, uma nova lacuna precisa ser preenchida, a das monografias de acessso aberto! Este aspecto negativo já foi apontado recentemente pelo Seminar on the Acquisition of Latin American Library Materials (SALALM, 2020):

5. Considerando que, os modelos pioneiros de acesso aberto cooperativo como o SCIELO e REDLYC tornaram os periódicos acadêmicos da região amplamente disponíveis por mais de duas décadas, mas ainda há uma lacuna para monografias (grifo nosso).

Apesar de todo o impacto devastador que a Covid-19 está provocando em todos nós, o momento mostrou como é possível mudar rapidamente hábitos e mentalidades previamente arraigadas. Considere, por exemplo, a capacidade de uma grande proporção da força de trabalho agora exercer as suas atividades com a mesma eficácia em casa - o home office ou teletrabalho, sem as viagens e o impacto ambiental causado por deslocamentos de longa distância para reuniões e conferências em todo o mundo. Teve início a época das lives, primeiramente com artistas populares e, em seguinte, também com arquivistas, bibliotecários e museólogos!

A mídia têm apontado que essa pandemia está causando mudanças nos variados setores da vida humana. As especulações como seria o novo "normal" está na ordem do dia nos veículos da comunicação de massa. De qualquer forma, parece que muita coisa não será como antes. 
Neste terceiro número da RICl em 2020, foram selecionados para publicação 11 artigos, duas revisões da literatura e um documento sobre a teoria arquivística.

Boa leitura e até o nosso próximo número!

\section{Referências}

BELLI, S.; et al. Coronavirus mapping in scientific publications: When science advances rapidly and collectively, is access to this knowledge open to society? Scientometrics, n. 124, p. 26612685 , July 2020. DOI: $10.1007 / \mathrm{s} 11192-020-03590-7$

BRASIL. Decreto no 10.316, de 7 de abril de 2020. Regulamenta a Lei $n=13.982$, de 2 de abril de 2020, que estabelece medidas excepcionais de proteção social a serem adotadas durante o período de enfrentamento da emergência de saúde pública de importância internacional decorrente do coronavírus (covid-19). Diário Oficial da União, 7 de abril de 2020. Disponível em: http://www.planalto.gov.br/ccivil 03/ ato20192022/2020/decreto/d10316.htm Acesso em: 2 de agosto de 2020.

FEBAB. Informação em quarentena. Disponível em; http://www.febab.org.br/2020/04/02/informacao-em-quarentena/ Acesso em: 10 agosto 2020.

SEMINAR ON THE ACQUISITION OF LATIN AMERICAN LIBRARY MATERIALS (SALALM). SALALM resolution: collection development in the time of covid-19. Disponivel em: https://salalm.org/salalm-resolution-collection-development-in-the-time-of-covid-19/ Acesso em: 9 de agosto de 2020. 